\title{
[Full Paper
}

\section{Computer simulation of electrophoretic transport \\ I. General procedure and an application to isoelectric focusing of proteins using carrier ampholytes}

\author{
Kazuo Shimao
}

\begin{abstract}
SUMMARY
A new, simple and versatile computer simulation procedure using NEC $9821 A p / \mathrm{u} 7$ for electrophoretic transport under constant voltage, wattage and current was devised. As an example of applications, simulation of isoelectric focusing (IEF) of proteins using carrier ampholytes is shown.
\end{abstract}

Key words : isoelectric focusing, computer simulation, protein.

Computer simulation (CS) of electrophoretic transport has been extensively reported by Bier and his colleagues since 1983., ${ }^{1,2}$ Their procedures are restricted only to simulation under constant current operation for various types of electrophoresis. A new, general and versatile procedure for iCS of electrophoretic transport which can be applied to three different types of electrophoretic conditions, i. e., electrophoresis under constant current, voltage and wattage, was devised and as an example of applications CS of isoelectric focusing of proteins using carrier ampholytes is reported in this paper.

\section{METHODS}

\section{Basic assumptions}

Medium for electrophoresis is assumed to have unit cross-sectional area and only electrophoretic and diffusional transports are taken into account.

Basic equations for electrophoretic and diffusional transports are the same as those used in the previous reports..$^{3,4)}$

All components in the system have known physico-chemical constants such as numbers and $\mathrm{p} K \mathrm{~s}$ of dissociation groups, ionic mobilities, diffusion coefficients etc., and electric neutrality holds throughout the medium.

\section{Description of the system}

An electrophoretic medium, $L+d x \mathrm{~cm}$ long is devided into $N+1$ segments with equal length, $d x$, numbered from anodic to cathodic end as 0 to $N$ so that $d x=L / N$.

Electrophoretic system is composed of $n$ components and molar concentration of $j$-th component in $i$-th segment at time $t$ is expressed as $C(j, i, t)$. Values of $C(j, i, 0) \mathrm{s}(j=1$ to $n, i=0$ to $N)$ are given as an initial condition.

Boundary conditions of the system are given by compositions of the end segments, $C(j, 0, t) \mathrm{s}$ and $C(j, N, t) \mathrm{s}(j=1$ to $n)$, which are independent on time $t$ and equal to compositions of the anolyte and the catholyte, respectively.

島尾和男; Densitometer Research Laboratory.

Correspondence address : Kazuo Shimao, 4-22-29 Nukui, Nerima-ku, Tokyo 176, Japan.

(Received September 4, 1993, Accepted November 8, 1993)

Abbreviations : IEF, isoelectric focusing; CS, computer simulation; PG, potential gradient. 
An elementary step to get $C(j, i, t+d t)$ s from $\boldsymbol{C}(\boldsymbol{j}, \boldsymbol{i}, \boldsymbol{t}) \mathrm{s}$

1) $\mathrm{pH}(i, t) \mathrm{s}(i=0$ to $N)$ of $i$-th segment at time $t$ are calculated by using electric neutrality condition of each segment.

2) Conductivities, $\kappa(i, t) \mathrm{s}(i=0$ to $N)$ of $i$-th segment at time $t$ are calculated.

3-1) Current density is constant and $I(t)=I_{0}$ for constant current operation.

3-2) For constant voltage operation at terminal voltage of $V_{0}$, current density at time $t$ is calculated by

$$
I(t)=V_{0} /\left(\sum_{i=0} \text { to } N(d x / \kappa(i, t))\right)
$$

3-3) For constant wattage operation at power $P_{0}$, current density at time $t$ is calculated by $I(t)=\left(P_{0} /\left(\sum_{i=0} \text { to } N(d x / \kappa(i, t))\right)\right)^{1 / 2}$

4) Potential gradients (PGs) at $i$-th segment, $\mathrm{PG}(i, t) \mathrm{s}(i=0$ to $N)$ are calculated by $\mathrm{PG}(i$, $t)=I(t) / \kappa(i, t)$.

5) Mobilities of $j$-th component in $i$-th segment, $u(j, i, t) \mathrm{s}(j=1$ to $n, i=0$ to $N)$ are calculated from physico-chemical constants of the components and $\mathrm{pH}(i, t) \mathrm{s}$, and migration velocities of $j$-th component in $i$-th segment, $v(j, i, t)$ s are calculated by $v(j, i, t)=u(j, i, t)$ $\mathrm{PG}(i, t)(j=1$ to $n, i=0$ to $N)$.

6) Maximum value of absolute values of $v(j$, $i, t)_{\mathrm{s}}$ is expressed as $V_{\mathrm{m}}$ and $d t$ for CS at time $t$ is calculated by $d t=0.95 d x / V_{\mathrm{m}}$.

7) $C(j, i, t+d t) \mathrm{s}(j=1$ to $n, i=1$ to $N-1)$ are calculated by

$$
\begin{aligned}
C(j, i, t+d t)= & C(j, i, t)\left(1-\frac{|v(j, i, t) d t|}{d x}\right) \\
& +C(j, i-\operatorname{sgn}, t) \\
& \cdot \frac{(\operatorname{sgn}) v(j, i-\operatorname{sgn}, t) d t}{d x} \\
& +D_{j} d t(C(j, i+1, t) \\
& -2 C(j, i, t) \\
& +C(j, i-1, t)) /(d x)^{2},
\end{aligned}
$$

where, sgn is sign of $v(j, i, t)$ and is equal to 1,0 and -1 , respectively, for positive, zero and negative values of $v(i, j, t)$.

The first term of the above expression is the amount of $j$-th component in $i$-th segment at time $t$ which-still remains in the $i$-th segment at time $t+d t$, and the second term is the amount that flows from the neighbouring segment during $d t$ electrophoretically. Thus, these two terms give the result of electrophoretic transport and the third term is a wellknown diffusional transport. An elementary step is repeated to simulate electrophoretic migration of components of the system.

\section{Computer program}

My program in $\mathrm{N}_{88}$ Basic (NEC) was run on NEC Model $9821 A p / \mathrm{u} 7$ personal computer. Hard copies of patterns on NEC MultiSync display were taken by NEC PC-PR 1000/4 page printer to obtain graphic representations of the CS.

Table 1. Physico-chemical input data of anolyte, carrier ampholytes and catholyte.

\begin{tabular}{lcccc}
\hline Component & $\mathrm{p} K \mathrm{a}$ & $\mathrm{p} K \mathrm{~b}$ & $\mathrm{p} I$ & $\begin{array}{l}\text { Mobility } \\
10^{-4} \mathrm{~cm}^{2} / \mathrm{V} \cdot \mathrm{s}\end{array}$ \\
\hline $\begin{array}{l}\text { Anolyte } \\
\text { Carrier ampholytes, }\end{array}$ & 2.0 & - & - & $\begin{array}{c}-2.3 \\
2.5\end{array}$ \\
$\begin{array}{r}i=1-20 \\
\text { Catholyte }\end{array}$ & $-5+7(i-1) / 19$ & & \\
\hline
\end{tabular}

\begin{tabular}{|c|c|c|c|}
\hline \multirow[t]{2}{*}{ Protein } & \multicolumn{2}{|c|}{0 ; Albumin } & $1 ; \gamma$-Globulin \\
\hline & $\mathrm{p} K \quad \mathrm{~N}$ & Number 0 & f residues \\
\hline \multirow[t]{5}{*}{ Acidic residues } & 3.5 & 1 & 4 \\
\hline & 4.0 & 50 & 48 \\
\hline & 4.4 & 80 & 69 \\
\hline & 8.0 & 4 & 32 \\
\hline & 10.5 & 16 & 60 \\
\hline \multicolumn{2}{|c|}{ Total acidic residues } & 151 & 213 \\
\hline \multirow[t]{4}{*}{ Basic residues } & 6.5 & 15 & 26 \\
\hline & 8.0 & 1 & 4 \\
\hline & 10.5 & 58 & 89 \\
\hline & 12.5 & 24 & 45 \\
\hline \multicolumn{2}{|c|}{ Total basic residues } & 98 & 164 \\
\hline \multicolumn{2}{|c|}{$\begin{array}{l}\text { Mobility of monovalent cation } \\
\left(10^{-6} \mathrm{~cm}^{2} / \mathrm{V} \cdot \mathrm{s}\right)\end{array}$} & 2.5 & 2.0 \\
\hline \multicolumn{2}{|c|}{$\begin{array}{l}\text { Diffusion coefficient } \\
\left(10^{-7} \mathrm{~cm}^{2} / \mathrm{s}\right)\end{array}$} & 6.0 & 4.0 \\
\hline \multicolumn{2}{|c|}{ Isoelectric point } & 4.73 & 7.98 \\
\hline
\end{tabular}

Diffusion coefficient was obtained by multiplying mobility by $z R T / F=0.02569$, where $z$ : valency, $R:$ gas constant, $T:$ absolute temperature, $F:$ Faraday's constant.

Table 2. Physico-chemical input data of proteins 0 and 1. 


\section{RESULTS AND DISCUSSION}

As an example of application of the CS procedure, simulation of IEF of two model proteins using 20 carrier ampholytes in a medium $10 \mathrm{~cm}$ long was performed. $N=100$ and $d x=0.1 \mathrm{~cm}$.
The two model proteins 0 and 1 are those of serum albumin and $\gamma$-globulin, respectively, and are the same as those in the previous report. ${ }^{3,4}$ ) Physico-chemical constants of an anolyte, carrier ampholytes and a catholyte are shown in Table 1 and those of the proteins in Table 2.

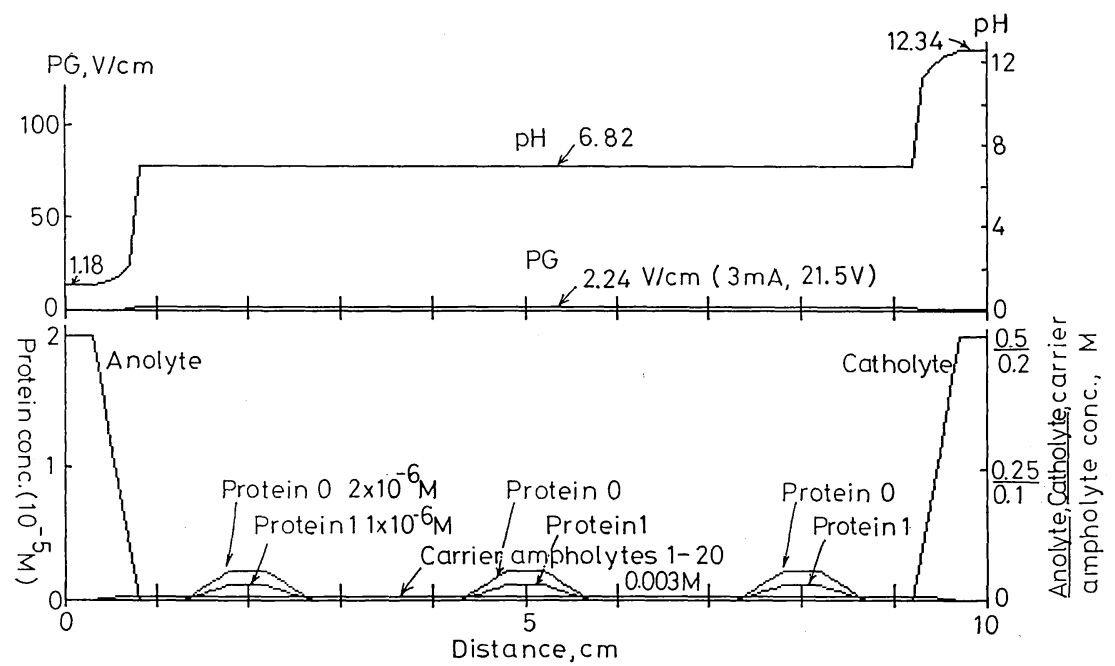

Fig. 1. Initial condition of CS.

Concentrations of components (bottom) and PG and $\mathrm{pH}$ (top) are shown. PG, current and voltage values are those for constant current operation at $3 \mathrm{~mA}$. Initial current and voltage for constant wattage operation at $1 \mathrm{~W}$ are $11.8 \mathrm{~mA}$ and $84.7 \mathrm{~V}$, respectively. Initial current for constant voltage operation at $100 \mathrm{~V}$ is $14.0 \mathrm{~mA}$.

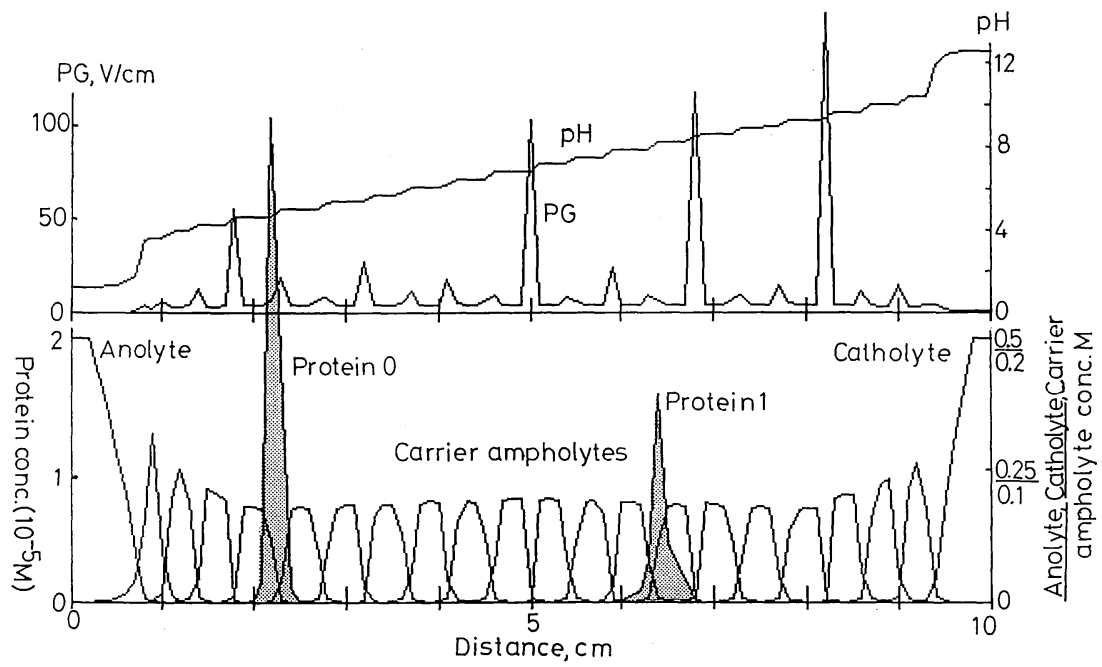

Fig. 2. CS of IEF for constant wattage operation at $1 \mathrm{~W}$ after 33,000 elementary steps.

Time of electrophorésis is $22,741 \mathrm{~s}(6.3 \mathrm{~h})$, voltage $146.3 \mathrm{~V}$ and amperage $6.83 \mathrm{~mA}$. 


\section{生物物理化学 $1994 ; 38: 224$}

Initial condition shown in Fig. 1 was set for constant voltage, wattage and current operations. The two model proteins started electrophoresis from three different positions and CS was continued to final state when the two proteins from different positions focused to the respective isoelectric zones. The results for constant wattage, voltage and current operations are shown in Fig. 2, 3 and 4, respectively. Time of CS was 1 hour per 100 elementary steps for the three modes of operations. These figures show clearly that the CS procedure reported here successfully simulates

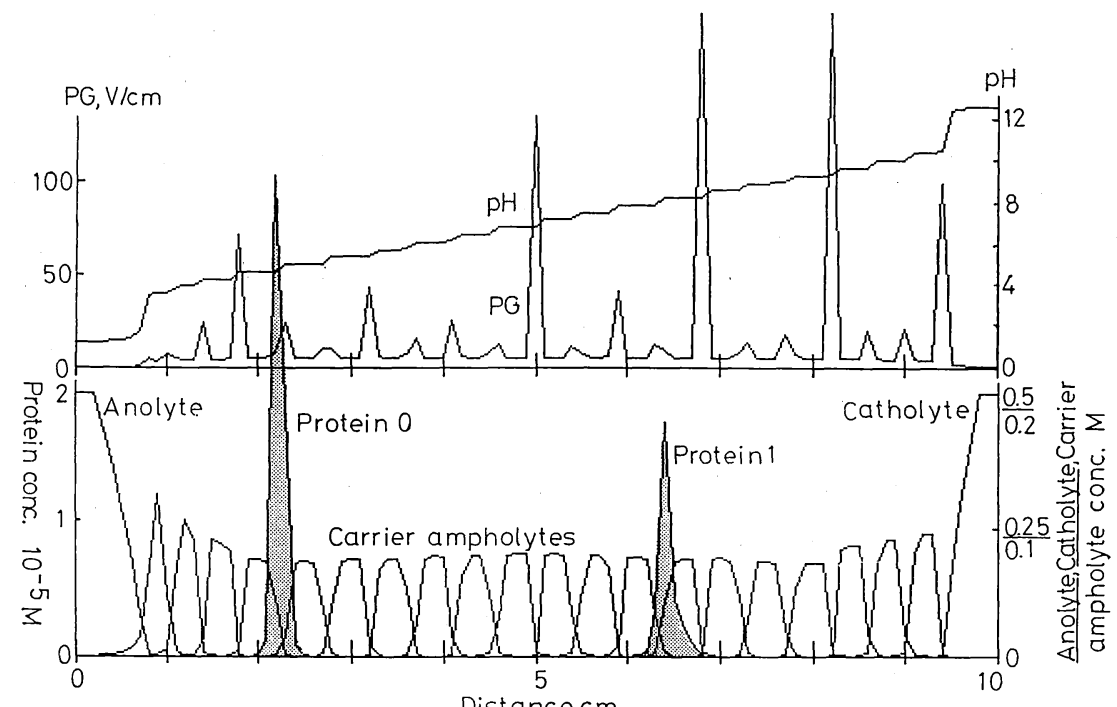

Fig. 3. CS of IEF for constant voltage operation at $100 \mathrm{~V}$ after 7,000 elementary steps.

Time of electrophoresis is $187,74 \mathrm{~s}(5.2 \mathrm{~h})$ and amperage $5.25 \mathrm{~mA}$.

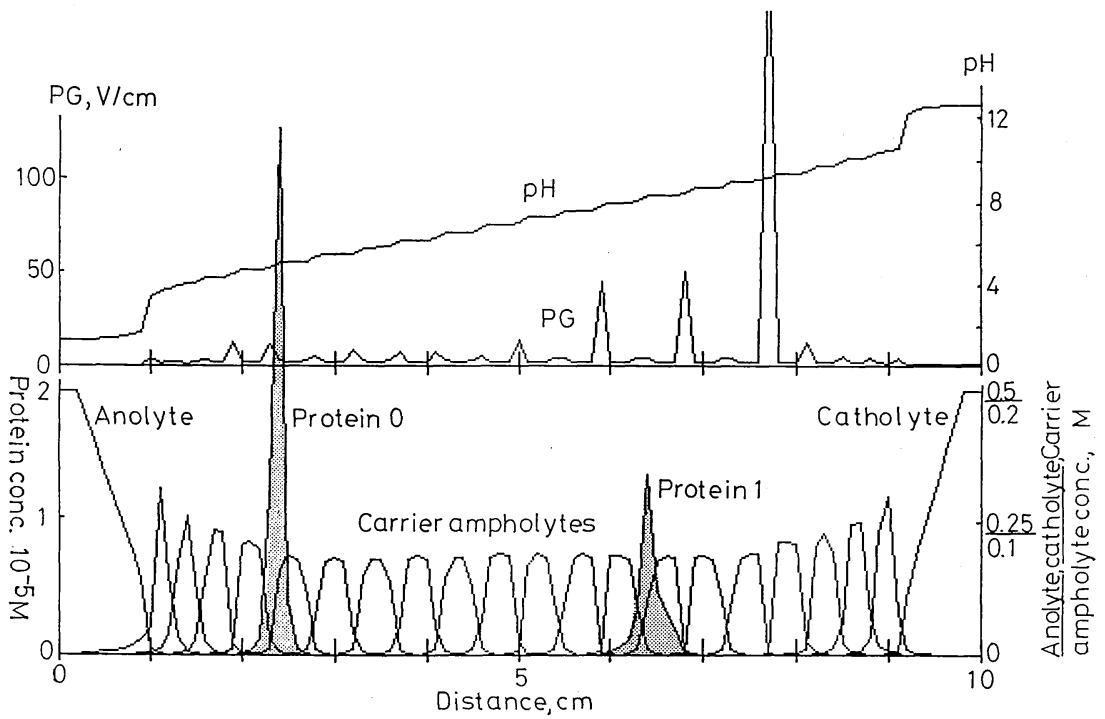

Fig. 4. CS of IEF for constant current operation at $3 \mathrm{~mA}$ after 12,000 steps of elementary steps.

Time of electrophoresis is $41,615 \mathrm{~s}(11.6 \mathrm{~h})$ and voltage $62.8 \mathrm{~V}$. 
electrophoretic transport for the three different modes of electrophoretic operations. Contrary to the discussion by Mosher et al, ${ }^{5)}$ my models for electrophoretic behavior of proteins ${ }^{3,4)}$ worked well not only in IEF as shown here but also for isotachophoresis and other modes of electrophoresis which will be reported in separate papers.

Stepwise pH curves and very uneven PG curves are the results of small number, i. e. 20, of carrier ampholytes that was unavoidable in the present situation of using personal-level computer. As high value of PG makes $d t$ for elementary step of CS small, resulting in long time of computation to reach steady of IEF, voltage, wattage and current values for respectively constant operations were forced to take small values compared to the values used experimentally. These situations are similar to the works of Bier's group. ${ }^{1,2,5)}$

Concerning PGs in the medium, diffusional currents carried by ionic constituents must be taken into account to get accurate values. Relation between accurate potential gradient, $P G$, and potential gradient neglecting diffusional currents, $P G_{0}$, is

$$
P G=P G_{0}\left(1-I_{\text {diff }} / I_{\text {total }}\right)
$$

where, $I_{\text {diff }}$ and $I_{\text {total }}$ are diffusional and total currents, respectively. Because diffusional currents were found to be less than $3 \%$ of the correspond- ing total currents and the use of $P G$ or $P G_{0}$ made little difference of the results of CS during the previous study, ${ }^{6)} P G_{0}$ s were used in this report. In spite of these limitations the CS procedure reported here can be expected to give useful suggestions to various types of electrophoresis experiments.

\section{REFERENCES}

1) Bier, M, Palusinski OA, Mosher RA, Saville DA. Electrophoresis : Mathematical modeling and computer simulation. Science 1983; 219: 1281-7.

2) Mosher RA, Saville DA, Thormann W. The dynamics of electrophoresis. Weinheim : $\mathrm{VCH}$, $1992: 71-229$.

3) Shimao K. Mathematical simulation of isotachophoresis boundary between protein and weak acid. Electrophoresis 1986; $7: 297-303$.

4) Shimao K. Mathematical simulation of steady sate isoelectric focusing of proteins using carrier ampholytes. Electrophoresis 1987; 8: 14-9.

5) Mosher RA, Dewey D, Thormann W, Saville DA, Bier M. Computer simulation and experimental validation of the electrophoretic behavior of proteins. Anal Chem 1989; 61: 362-6.

6) Shimao K. Computer simulation of isoelectric focusing of carrier ampholytes. Physico-Chem Biol (Seibutsubutsurikagaku) 1993; $37: 70$. 